\title{
A transparência na publicação eletrônica das informações municipais disponíveis em suas homepages: uma análise dos municípios pertencentes ao Corede Produção/RS
}

\author{
Giovani Castoldi* \\ Sandra Regina Toledo dos Santos**
}

\begin{abstract}
Resumo
Este artigo se destina a avaliar a forma como os municípios pertencentes ao Corede Produção/RS estão fornecendo os dados relacionados aos seus atos de gestão, de modo que a sociedade local possa acompanhar as informações da administração pública municipal, uma vez que os meios eletrônicos favorecem a fiscalização do cidadão sobre os atos realizados pela administração pública. A metodologia consiste em uma pesquisa com uma abordagem quantitativa, de natureza exploratória. A coleta de dados, realizada por meio do acesso ao conteúdo das páginas web dos 21 municípios estudados, foi dividida em três etapas. Na primeira fase, os resultados mostram que os municípios estudados publicam informações gerais em suas homepages, porém organizadas de uma maneira que dificulta o acesso básico pelos usuários. Na segunda fase, em que constam os itens referentes à contabilidade e à gestão dos recursos públicos, os melhores resultados encontrados relacionavam-se à exposição da informação que demonstra orçamento e transações financeiras, exceto quanto aos pagamentos a fornecedores, dado ainda indisponível à população. Finalmente, a terceira etapa aborda a publicação dos aspectos jurídicos da gestão, tendo a maioria dos municípios aderido ao processo de transparência informativa, a fim de contribuir para a gestão democrática.
\end{abstract}

Palavras-chave: Informação. Publicação. Sites. Transparência.

* Graduado em Ciências Contábeis - UPF/RS. E-mail

** $\quad$ Mestre em Ciências Contábeis/Controladoria - Unisinos/RS, Professora Pesquisadora Adjunto I - UPF/RS. E-mail 


\section{Introdução}

As dificuldades encontradas no processo de gestão da administração pública, principalmente no que se refere à otimização dos recursos financeiros, tornou necessária a qualificação das políticas de controle e de acompanhamento dos atos de governo nesses entes. Como mecanismo principal para atingir essa meta e para cumprir a característica democrática do governo - que visa à responsabilização dos gestores e ao amplo acesso da sociedade às informações - surgiu a disseminação da transparência como requisito essencial.

A responsabilidade na gestão dos recursos governamentais e da moralidade pública ganha cada vez mais visibilidade no cenário político atual, marcado pelo desafio de uma gestão mais eficiente, com a crescente demanda pelos serviços e a racionalização necessária nos gastos incorridos durante a execução. No Brasil, a busca pelo fortalecimento da democracia, mesmo que tardia, é marcada pela procura de instituições formais e de mecanismos voltados ao controle e à fiscalização dos atos do governo (BUGARIN; VIEIRA; GARCIA, 2003, p. 13).

Os sistemas de controles institucionais internos e formais do setor público devem ser acompanhados, também, da fiscalização pela sociedade, devendo o governo criar medidas que incentivem o acesso da população a essas informações e a discussão sobre as formas de aplicação dos recursos orçamentários (LINO, 2001, p. 162).

Nesse sentido, a busca por controles internos melhor aperfeiçoados, com informações mais claras e sólidas, conforme proposto e implementado na iniciativa privada, levou a que o setor público começasse a adaptar, diante das necessidades, os instrumentos de gestão e de controles padronizados. Assim, surgiram mudanças na legislação para tornar obrigatória essa tendência legal, com destaque à Lei Complementar 101/2000. Conhecida como a Lei da Responsabilidade Fiscal (LRF), ela é marcada pela busca do equilíbrio das contas públicas e pela sustentabilidade financeira, primando pela responsabilidade e transparência da gestão através da evidenciação das informações contábeis à sociedade (SILVA; AMORIM; SILVA, 2004, p. 19). Na conceituação de Magalhães et al. (2005, p. 11), a LRF "veio promover uma mudança institucional e cultural na forma de administrar os recursos públicos, dinheiro da sociedade".

O avanço das tecnologias de informação e comunicação nos últimos anos colaborou com esse processo, pois facilitou e deu agilidade ao acesso das informações pela sociedade. Nessa perspectiva, pode-se considerar o meio eletrônico um poderoso instrumento para a efetivação da transparência dos atos do governo (SOUZA et al., 2008, p. 2).

Os mecanismos de transparência pública, apesar de relativamente novos, configuram-se como importantes elementos no processo democrático e participativo da população para a consolidação das políticas regionalizadas, estreitando as relações 
entre os interessados. Nesse contexto, este artigo objetiva responder à seguinte questão: que informações os municípios do Conselho Regional de Desenvolvimento da Produção (Corede Produção)/RS têm disponibilizado, em suas homepages, relacionadas aos atos de gestão de seus governos? Como objetivo geral, pretende-se avaliar as informações disponibilizadas eletronicamente pelos municípios do Corede Produção/RS, no que se refere aos atos de gestão de seus governos. Já os objetivos específicos consistem em descrever a composição das informações disponíveis nas homepages dos municípios selecionados e evidenciar como esses municípios têm aderido à divulgação eletrônica das informações para a transparência governamental.

Considerando a importância da transparência dos atos públicos como mecanismo de controle social e de exercício de democracia, a publicidade das informações através de meios de comunicação com fácil acesso busca responder aos anseios da sociedade e incentivar um maior acompanhamento dos atos dos entes públicos pelo cidadão.

Este artigo se justifica por abordar a necessidade de acompanhamento sistemático dos cidadãos quanto ao gerenciamento dos recursos municipais e à transparência dos atos que incidem nas movimentações financeiras e administrativas. Outro fator que o justifica diz respeito à necessidade de estabelecer um nexo entre o que a legislação preconiza no avanço dos sistemas eletrônicos de publicidade e o modo como tais informações estão sendo divulgadas pelos gestores municipais.

Este texto compreende cinco seções, iniciando-se por esta introdução. Na segunda seção, é apresentado o referencial teórico, seguido, na terceira, da metodologia empregada na realização do estudo. Na quarta seção, estão os resultados e, na quinta, apresentam-se as conclusões, seguidas das referências bibliográficas.

\section{Referencial teórico}

Nesta seção, são apresentados os aspectos relacionados à gestão na administração pública, às mudanças ocorridas no gerenciamento governamental e às inovações decorrentes da LRF na divulgação eletrônica de dados e para a transparência.

\subsection{A gestão na administração pública}

A administração pública preconiza as atividades do governo necessárias para atender aos cidadãos. Para tanto, as estruturas físicas e administrativas nas esferas governamentais requerem a organização de métodos e processos que viabilizem o desenvolvimento das atividades que lhes são correlatas. 
De acordo com Araújo e Arruda (2009, p. 2), a administração pública é conceituada como o "conjunto de funções que visam à boa gestão da res pública (ou seja, da propriedade pública), de modo a possibilitar que os interesses da sociedade sejam alcançados”.

Por sua vez, a atividade administrativa é definida por Kohama (2003, p. 30) como sendo formada por um "conjunto de órgãos, convencionalmente chamados Administração", por meio do qual "o Estado pratica a gestão de atividades que lhe são próprias, por corresponderem ao interesse público". Gasparini $(2011$, p. 56) corrobora a afirmação do autor, sintetizando que se trata da "gestão, nos termos da lei e da moralidade administrativa, de bens, interesses e serviços públicos visando o [sic] bem comum".

O enquadramento dado por Araújo e Arruda (2009, p. 2) é de que a administração pública age como um conjunto de órgãos destinados a cumprir as finalidades do Estado na busca do bem comum. Segundo os autores, o conceito de Estado refere-se à "organização político-jurídica de uma sociedade para realizar o bem público/comum, com governo próprio e território determinado".

$\mathrm{Na}$ ótica de Meirelles et al. (2011), o conceito de administração pública, por muitas vezes, não oferece contornos bem definidos, seja pela diversidade de sentidos da própria expressão, seja pelos diferentes campos em que se desenvolve essa atividade. Assim, os autores apontam que a expressão "Administração Pública" pode ser utilizada para designar tanto pessoas e órgãos governamentais como a atividade administrativa em si.

$\mathrm{Na}$ forma de gerir a máquina pública, estão contemplados os requisitos legais que definem a sistematização desses entes, bem como a vinculação aos atributos de organização formal e administrativa, na qual os servidores públicos desempenham suas atividades em prol da sociedade.

Em uma perspectiva histórica, Slomski (2003, p. 358) relata que, até meados do século XX, o Estado era composto de um pequeno núcleo estratégico responsável por questões básicas, tais como a defesa nacional, a arrecadação e a diplomacia. Conforme o autor, a função social do Estado como conhecemos hoje começou a surgir apenas com a Segunda Guerra Mundial, por meio da oferta de serviços como saúde, educação e transportes. Dessa forma, a necessidade do aumento da estrutura funcional do Estado tornou-se iminente, refletindo no excesso de pessoal vinculado aos quadros efetivos de servidores e na burocratização do sistema.

$\mathrm{Na}$ continuidade desse entendimento, o mesmo autor destaca que, por conta dessa evolução do Estado, a administração pública precisou evoluir em três modelos básicos: o patrimonialista, caracterizado pela confusão entre os bens públicos e 
de seus agentes; a administração burocrática, caracterizada pela impessoalidade e pelo formalismo e, enfim, a administração pública gerencial, orientada por resultados e voltada às necessidades sociais com menor custo.

Sob tais aspectos, a administração pública possui diferenças conceituais, conforme destacam os autores. Contudo, em linhas gerais, percebe-se a vinculação do Estado como agente propulsor no atendimento das demandas da sociedade e a estrutura hierárquica estabelecida por diferentes graus de autoridade em sua organização funcional.

\subsection{As mudanças ocorridas no gerenciamento das atividades governamentais}

$\mathrm{Na}$ busca por aperfeiçoamento das atividades governamentais, torna-se evidente a inserção de novas metodologias de trabalho, no intuito de promover uma concepção mais eficiente e com maior amplitude sobre os diversos setores administrativos, para afastar o já comprometido modelo que revelava excesso de burocracia.

Com as mudanças mundiais, marcadas inicialmente pela crise econômica de 1929, que trouxeram a necessidade de os países buscarem formas internas de produção e diminuição nas importações, os Estados passaram a aumentar sua indústria de base e a buscar uma função mais intervencionista na economia (SILVA; MACEDO; 1998, p. 3).

Santos (2003, p. 1) lança a concepção de que a primeira tentativa de implementar no Brasil a administração pública gerencial ocorreu na década de 1960, durante o governo Castelo Branco, com o Decreto 200/67, que promovia uma processo de descentralização da administração pública, transferindo as atividades de produção de bens e serviços para autarquias, fundações, empresas públicas e sociedades de economia mista.

Bresser Pereira (1996) enfatiza que a administração pública burocrática surgiu como substituição do modelo anterior, marcado pelo patrimonialismo e característico das monarquias absolutas, em que o patrimônio privado de seus agentes era confundido com o público, ensejando altos níveis de nepotismo e corrupção. Conforme o autor, o surgimento do capitalismo e da democracia aponta para a necessidade de separação clara entre o público e o privado, assim como entre o Estado e o mercado, originando a administração burocrática moderna racional-legal.

No entanto, segundo o mesmo autor, apesar de representar um grande avanço em comparação ao modelo anterior, o modelo burocrático mostrou-se ineficiente. No decorrer do século XX, o crescimento social e econômico do Estado resultou em problemas como lentidão nos processos, alto custo e ineficiência, pois não estava orientado para o atendimento das demandas internas e externas. 
De acordo com Pereira (2004), na década de 1980 deu-se o surgimento de uma tendência mundial de reformas de Estado na busca de modernizar a administração pública. Nesse processo, tem início a procura pela substituição dos processos marcados pelo modelo burocrático por novo modelo com características gerenciais, pautado em princípios que já estavam vinculados à administração privada.

Sob o aspecto econômico, Bresser Pereira (2006, p. 21) destaca que, nessa mesma década, a atenção da política pública mundial estava focada em questões estruturais, como ajustes fiscais e reformas voltadas ao mercado diante de crises de endividamento internacional. Tais medidas auxiliaram na superação dos efeitos dessa crise, como o controle das balanças de pagamento e de taxas de inflação.

Contribuindo com essas perspectivas, Rezende (2009) relata que as reformas gerenciais ocorridas na década de 1990 estavam relacionadas, principalmente, a essas demandas e buscavam redefinições dos modelos de gestão. Tais reformas visavam, segundo o autor, ao estabelecimento de novos modelos institucionais que pudessem ampliar e melhorar a capacidade de governar, a legitimidade política e a eficiência nas ações do governo.

Ao elencar as características que distinguem a administração burocrática e a gerencial, Pereira (2004, p. 15) destaca, dentre outras: a mudança da racionalidade absoluta para as atividades focadas nos resultados, a rigidez no controle dos processos para a instituição de indicadores de desempenho e controle de resultado aos agentes públicos e, ainda, a descentralização como medida administrativa.

Como regramento instituído para permitir tais reformulações, Ramos Júnior (2011) enfatiza que a Emenda Constitucional 19/1998 permitiu inserir a eficiência como um princípio constitucional da administração pública, como forma de diminuir o descontentamento da sociedade com as deficiências na prestação dos serviços públicos no Brasil. Entende-se que, por várias décadas, tem-se buscado otimizar o uso dos recursos públicos com vistas a proporcionar um fluxo de procedimentos mais regrados e espelhados na sistematização administrativa, em padrões já utilizados pela iniciativa privada. No entanto, esse movimento ainda encontra restrições na efetiva implantação de métodos eficazes de gerenciamento, em virtude dos regramentos legais que são impostos às atividades inerentes ao Estado.

\subsection{As inovações decorrentes da LRF na divulgação eletrônica de dados e para a transparência}

Desde a implantação da LRF, em 2000, a gestão pública tem adaptado suas estruturas no que se refere à consolidação das informações para atender aos dispo-

sitivos da lei e estabelecer um processo de acompanhamento contínuo para fins de 
controle e de atendimento aos índices legais estabelecidos, a fim de que posteriormente ocorra a divulgação nos canais de comunicação.

Os relatos de Figueiredo (2001, p. 27) demonstram que o desequilíbrio fiscal dos entes do governo público tem suas raízes nas deficiências do planejamento governamental, devido as suas más práticas orçamentárias. $\mathrm{O}$ autor ainda observa que, historicamente, os orçamentos públicos foram realizados sem respeitar a adequação na fixação das despesas, levando em conta a estimativa das receitas para um determinado período. Tal fato gerava uma inversão dessa ordem, inicialmente determinando o valor dos gastos entendidos como necessários, para só então adequar a receita equivalente para a devida quitação, sem que houvesse correlação entre o orçamento e a realidade planejada.

No entendimento de Magalhães et al. (2005, p. 2), para realizar seu trabalho e prestar contas de forma eficiente, o gestor público depende de instrumentos que proporcionem informações corretas sobre a organização por meio de sistemas capazes de gerá-las de modo eficiente. Conforme o autor, o sistema contábil reflete ao administrador a real situação patrimonial e financeira da instituição.

Complementando essa concepção, Oleiro, Mendes e Quintana (2008, p. 7) destacam que a gestão orçamentária, financeira e patrimonial do governo deve seguir normas e princípios contábeis preconizados pela ciência contábil, especialmente pela contabilidade pública, a qual é regulamentada pela Lei 4.320/64, onde são definidos todos os procedimentos inerentes ao setor público. Os autores observam que, nas últimas décadas, graças ao avanço tecnológico, a administração pública em geral implementou transformações na área de Tecnologia de Informação (TI), dentre as quais se destacam: a implantação de sistemas como o Sistema Integrado de Administração Financeira (Siafi), o Sistema Integrado de Administração de Pessoal (Siape) e o Sistema Integrado de Administração de Serviços Gerais (Siasg); a implantação de programas que promoveram melhorias nos controles internos e externos, com maior agilidade e eficiência técnica; o controle social e a transparência dos atos do governo; e a inserção de agentes de fiscalização social, trabalho realizado por organizações não governamentais (ONGs), sociedades civis, entre outras. Vinculados a esses acontecimentos, como mecanismos de controle e fiscalização, percebe-se que foram intensificados os processos das auditorias governamentais, essenciais à verificação e a emissões de pareceres sobre os demonstrativos contábeis.

Perez Júnior (2004, p. 37) afirma que a auditoria promove o levantamento, o estudo e a avaliação sistemática das transações, dos procedimentos, das rotinas e demonstrações contábeis das entidades, com o objetivo de fornecer aos usuários 
uma opinião imparcial sobre a adequação, as normas e os princípios que a regem. Na concepção de Tormem, Metzner e Braum (2011), as informações geradas pela contabilidade servem aos usuários internos, ao próprio Poder Executivo e aos controles externos, como o contribuinte, o Tribunal de Contas e demais entidades. Conforme o autor, a LRF incorporou obrigações em forma de lei para aumentar o acesso da sociedade a essas informações, tornando a sociedade civil mais próxima do acompanhamento e da fiscalização das contas públicas.

Silva, Amorim e Silva (2004, p. 17), que voltam especial olhar ao início do texto da LRF, apontam para o fato de que o regramento legal estabelece novas normas de finanças públicas atinentes à responsabilidade na gestão fiscal, abrangendo todas as esferas dos governos federal, estadual e municipal. Em outro direcionamento, Souza et al. (2008, p. 4) registram que a aprovação da LRF surgiu como instrumento para conter os déficits públicos e o endividamento crescente das unidades da Federação.

No entanto, Culau e Fortis (2006, p. 2) argumentam que a LRF não pode ser entendida como um fenômeno isolado, pois foi desenvolvida dentro de um contexto de busca de ajuste fiscal pelo governo, que remonta à década de 1990. Nesse processo, conforme os autores, foram sendo desenvolvidas reformas gerenciais que já permitiam mudanças, como enfoques na criação de metas e indicadores de desempenho, mecanismos de avaliação de resultados, gestão participativa e enfoques estratégicos nos programas do governo.

Partindo da abordagem do art. 163 da Constituição Federal, os direcionamentos de Silva, Amorim e Silva (2004, p. 21) remetem para a compreensão de que a LRF trouxe inovações no processo de planejamento público, pois, além de reforçar os mecanismos de controle e de transparência na aplicação dos recursos, atribui aos próprios administradores a responsabilidade pela sua gestão fiscal. Os mesmos autores concluem que, para a realização desses fins, é necessário, ainda, o aprimoramento de uma cultura - até então pouco praticada - de sistemas de fiscalização e controle, tanto internos quanto externos, considerando as vinculações políticas ou sociais.

De acordo com Veríssimo (2011, p. 2), são quatro os alicerces da LRF:

- o primeiro é o planejamento, o qual deve acontecer por meio da programação da execução orçamentária, da identificação dos objetivos e das metas prioritárias através do Plano Plurianual (PPA), da Lei de Diretrizes Orçamentárias (LDO) e da Lei Orçamentária Anual (LOA);

- o segundo elemento destacado é a transparência, uma vez que deverão estar à disposição da sociedade mecanismos de cunho democrático, destacando-se 
a participação em audiências públicas, a divulgação das informações gerenciais através do Relatório Resumido da Execução Orçamentária, do Relatório de Gestão Fiscal, bem como dos Anexos de Metas e Riscos Fiscais;

- o próximo elemento refere-se ao controle, pela necessidade de fiscalização rigorosa e contínua das atividades administrativas, exigindo atenção dos órgãos responsáveis pela sua realização, principalmente do Tribunal de Contas, e à responsabilidade dos sistemas de controle interno;

- por fim, tem-se a responsabilidade, que impõe ao gestor público o respeito à lei, sob pena de responder por seus atos e sofrer as sanções previstas.

Culau e Fortis (2006, p. 5) discutem a transparência proposta pela LRF, subdividindo essa questão em dois tópicos: os instrumentos de transparência fiscal e a criação do Portal da Transparência (PT) do Governo Federal na internet.

Quanto ao primeiro tópico, os instrumentos de transparência fiscal, de acordo com o próprio art. 48, no capítulo IX da LRF, "a transparência será assegurada também mediante incentivo à participação popular e realização de audiências públicas, durante os processos de elaboração e de discussão dos planos, lei de diretrizes orçamentárias e orçamentos". O texto é ampliado com a seguinte conotação:

São instrumentos de transparência da gestão fiscal, as quais será dada ampla divulgação, inclusive em meios eletrônicos de acesso público: os planos, orçamentos e leis de diretrizes orçamentárias; as prestação de contas e o respectivo parecer prévio; o Relatório Resumido da Execução Orçamentária e o Relatório de Gestão Fiscal; e as versões simplificadas desses documentos.

No que se refere ao segundo tópico, a criação dos PTs, conforme proposta da LRF, é determinada pela publicação dos atos de governo através da internet nos respectivos portais, considerados pelos autores uma inovação recente do governo em matéria de transparência de gestão pública.

No entendimento de Lino (2001, p. 162), a transparência dos gastos públicos é efetivada através da construção de um controle exercido pela sociedade, com objetivos voltados à criação de leis que incentivem e aumentem as possibilidades do acesso a tais informações. Dessa forma, a internet torna-se um veículo efetivo nesse processo, devendo ser incluídas outras informações, como é o caso dos relatórios de auditoria.

O relato de Veríssimo (2011, p. 7) evidencia que a transparência buscada pela lei aqui discutida visa a permitir um controle social mais efetivo do governo público. Para tanto, parte do pressuposto de que, conhecendo a situação em que se encontram as contas do governo, a sociedade cria e aumenta as condições de cobrança e fiscalização da gestão nos governos. Apesar dos avanços destacados pela LRF, 
Lopes (2011, p. 4) identifica pontos que precisam ser melhorados, dentre os quais a necessidade em aumentar a clareza das informações disponibilizadas, empregando uma linguagem simplificada para que a população que não domina termos técnicos possa, efetivamente, compreendê-las.

$\mathrm{Na}$ esteira da divulgação das informações do governo pela internet, surge 0 governo eletrônico, que "é hoje uma das principais formas de modernização do Estado, principalmente prestando serviços e informações e reestruturando a maneira como interagem com os cidadãos, empresas, servidores públicos e o próprio governo" (ALEXANDRINI et al., 2008, p. 2).

Dada a importância da disponibilização das informações públicas à sociedade, a abertura de espaços para sua participação e interatividade no processo decisório surge como mecanismo capaz de aproximá-la do governo, ao estimular a participação coletiva no gerenciamento da coisa pública. A resistência cultural na abertura de tais espaços participativos é, contudo, obstáculo para o desenvolvimento desse mecanismo de transparência (PINHO; SACRAMENTO, 2007, p. 2). Assim, sob o cenário de avanços tecnológicos e de popularização dos acessos à internet, os entes governamentais buscam adaptar-se à realidade e atender aos princípios que regulamentam as atividades públicas, aproximando-se da sociedade.

De acordo com Strieder (2004, p. 177) a transparência faz parte dos princípios éticos fundamentais para o exercício da democracia. Conforme o autor, a democracia é um sistema de governo em que o poder deve ser partilhado pelo povo em favor deste, colaborando para que a ocorrência de problemas como desvios, fraudes e corrupção diminua.

Para atender esse pressuposto, a transparência é um mecanismo muito mais amplo do que o princípio da publicidade elencado na Constituição Federal de 1988, uma vez que este se limita a prever a divulgação das ações governamentais, enquanto aquela vincula, também, o conhecimento e o entendimento da sociedade sobre o conteúdo divulgado. Dessa forma, percebe-se que a utilização dos meios eletrônicos, pela sua capacidade na divulgação de dados e agilidade no processo de comunicação, pode ser encarada como uma tendência importante na aproximação da sociedade e do governo, bem como na promoção da transparência dos procedimentos que envolvem os atos públicos, especialmente nos municípios. Assim, os recursos disponíveis devem permitir uma participação efetiva da população na administração pública, com uma ampla conscientização sobre a relevância do acompanhamento da gestão nos diversos níveis de governo. 


\section{Metodologia}

A pesquisa para obtenção das informações necessárias, quanto aos objetivos, é de cunho descritivo, conforme estabelecem Cervo e Bervian (2002).

A abordagem utilizada caracteriza-se como quantitativa, por buscar a quantificação das informações disponibilizadas nos sites, a fim de verificar como se dá a transparência dos atos públicos municipais. O delineamento baseia-se na sistemática de survey como procedimento técnico, nos municípios componentes da amostra.

Este estudo teve por base os dados do ano de 2010, considerando que o Estado do Rio Grande do Sul constituía-se por 496 municípios, dos quais foram objeto deste estudo somente aqueles pertencentes ao Corede Produção. Essa região é composta por 21 municípios: Almirante Tamandaré do Sul, Camargo, Carazinho, Casca, Chapada, Ciríaco, Coqueiros do Sul, Coxilha, David Canabarro, Ernestina, Gentil, Marau, Mato Castelhano, Muliterno, Nova Alvorada, Nova Boa Vista, Passo Fundo, Pontão, Santo Antônio do Palma, Santo Antônio do Planalto, São Domingos do Sul, Vanini e Vila Maria.

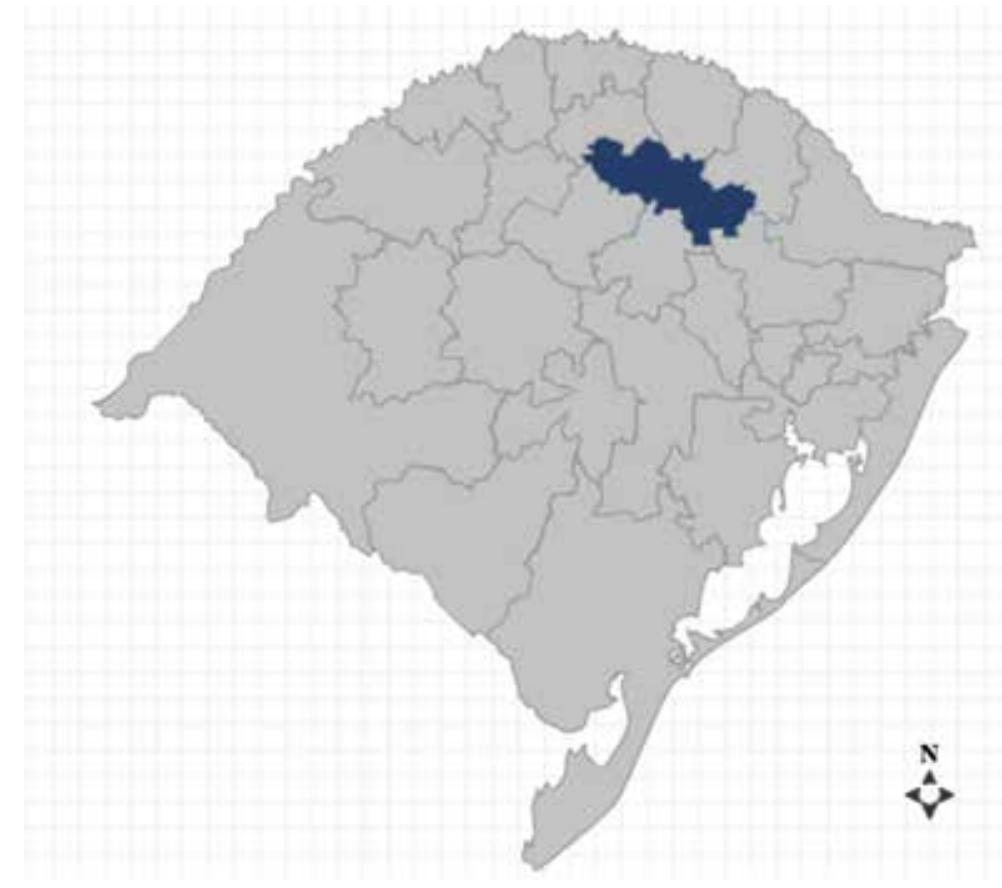

Fonte: FEE (2012).

Figura 1: Localização do Corede Produção 
Na Figura 1, visualiza-se a região do Corede Produção, a qual detinha uma população estimada em 349.200 habitantes, contando com um PIB per capita de $\mathrm{R} \$ 14.026,00$.

Cabe destacar, conforme Bandeira (2011, p. 1), que os Conselhos Regionais de Desenvolvimento, denominados de "Coredes", foram criados no Rio Grande do Sul com a finalidade de "contribuir nas articulações políticas, econômicas e sociais para promover o desenvolvimento regional no Estado como uma tentativa de institucionalização de uma nova escala territorial para a gestão pública, intermediária entre o próprio Estado e os municípios”, em virtude das desigualdades regionais em âmbito estadual.

O procedimento de análise deu-se pelo acesso às homepages dos locais definidos e pela coleta dos dados, entre agosto e novembro de 2011, com tabulação em planilha eletrônica. A análise foi procedida em três etapas: na primeira, realizou-se um levantamento das informações disponíveis em caráter geral para a população; na segunda, a busca deu-se por informações contábeis e de gestão dos recursos públicos; e, por fim, na terceira, foram levantadas as informações de aspectos legais dos atos públicos municipais.

\section{Resultados}

Na realização da primeira etapa deste estudo, o foco centrou-se na disponibilização das informações em caráter geral, tendo-se observado, inicialmente, o layout das homepages em todos os municípios, a fim de verificar se pode ser considerado simples e de fácil navegação.

Posteriormente, direcionou-se um especial olhar sobre a forma como são disponibilizadas outras informações à população, dados que foram distribuídos na Tabela 1 do seguinte modo:

- contatos por secretarias: identificação das secretarias do município (dados como telefone, endereço e e-mail);

- imprensa: notícias do município, calendário de eventos e outras informações sociais;

- apresentação com dados gerais: informações sobre o prefeito, o vice-prefeito, ex-prefeitos, localização do município, dados históricos, estatísticas e símbolos;

- cadastro de fornecedores: relação com a razão social, CNPJ e endereço de fornecedores;

- intranet: apresentação de link de acesso à intranet pelos servidores;

- serviços on-line: conteúdo referente à disponibilidade de sistemas de acesso relacionados aos tributos locais, como emissão de guias (IPTU e ISS), calendário fiscal, consulta de processos e emissão de CNDs. 
Tabela 1: Informações gerais disponíveis nas homepages dos municípios estudados

\begin{tabular}{l|c|c}
\hline \multicolumn{1}{c|}{ Etapa 1 } & $\begin{array}{c}N^{\circ} \text { de municípios com } \\
\text { informações encontradas }\end{array}$ & $\begin{array}{c}\text { No de municípios } \\
\text { com informações não } \\
\text { encontradas }\end{array}$ \\
\hline Contatos por secretarias & 21 & - \\
Imprensa & 3 & 18 \\
Apresentação do local com dados gerais & 21 & - \\
Cadastro de fornecedores & 4 & 17 \\
Link da intranet & 6 & 15 \\
\hline Serviços on-line disponíveis & \multicolumn{2}{|c}{18} \\
Emissão de guias ISS e IPTU & 3 & 20 \\
Calendário fiscal & 1 & 20 \\
Consulta de processos & 1 & 18 \\
Emissão de CNDs & 3 & \\
\hline
\end{tabular}

Fonte: Sites dos municípios consultados.

Pelos resultados dispostos na Tabela 1, é possível perceber que os municípios disponibilizam informações básicas aos cidadãos e que informações mais acuradas ainda não estão acessíveis para consulta.

Nota-se que os contatos das repartições públicas nas secretarias e a apresentação de dados gerais dos municípios são informações unânimes na divulgação eletrônica. Já a disponibilidade de acesso aos setores de imprensa é percebida em apenas três locais. Da mesma forma, os cadastros de fornecedores estão presentes em quatro dos portais visitados. Infere-se que, como forma de conferir transparência às compras públicas, a listagem dos fornecedores credenciados é um instrumento importante em termos de gestão, seja dos pontos comerciais e de serviços instalados nos próprios municípios, seja daqueles situados em outros locais.

O link da intranet foi visualizado em seis portais, representando $28,5 \%$ dos locais estudados. Esse mecanismo possibilita o acesso dos servidores às informações funcionais, como contracheque, registros do ponto, formulários para solicitações de adicionais e benefícios previstos na legislação. Entende-se que, quando esses acessos não estão visíveis, acabam por limitar o acompanhamento das atividades rotineiras que envolvem a situação funcional dos servidores.

Já nos serviços on-line, foram identificadas baixas incidências de divulgação eletrônica de dados aos usuários externos. Nesse quesito, somente três municípios - Passo Fundo, Marau e Carazinho - permitem a emissão de guias de IPTU e ISS para pagamento, bem como a obtenção de CND às empresas que necessitarem desse documento. Por sua vez, a disponibilização do calendário fiscal aos contribuintes e a permissão de consulta aos processos em tramitação estão presentes em um 
único local, a saber, o município de Passo Fundo. Essas informações revelam ser incipiente a presença de dados gerais relevantes ao cumprimento da transparência efetiva aos usuários internos e externos, os quais as utilizam para acompanhamento e buscas documentais importantes em suas atividades.

Na Tabela 2, buscou-se realizar a síntese de informações contábeis e de gestão dos recursos públicos na composição dos dados ilustrados nas homepages dos locais estudados, da seguinte forma:

- concursos: dados referentes a concursos públicos já realizados;

- prestação de contas e pareceres: dados sobre a prestação de contas de recursos obtidos ou concedidos;

- Relatório Resumido da Execução Orçamentária (RREO): apresentação conforme preconiza a LRF;

- Relatório de Gestão Fiscal (RGF): apresentação conforme preconiza a LRF, com informações relacionadas a despesas com pessoal, dívida consolidada líquida, garantias de valores, operações de créditos e restos a pagar;

- relação dos pagamentos efetuados: movimentação financeira para quitar fornecedores, com razão social, valores e origem da despesa;

- PPA: conteúdo do Plano Plurianual dos municípios estudados;

- LDO: conteúdo e movimentação da Lei de Diretrizes Orçamentárias nos municípios estudados;

- LOA: conteúdo e movimentação da Lei Orçamentária Anual nos municípios estudados.

Tabela 2: Informações contábeis e de gestão dos recursos públicos disponíveis nas homepages dos municípios estudados

\begin{tabular}{|c|c|c|}
\hline Etapa 2 & $\begin{array}{l}\mathrm{N}^{0} \text { de municípios com } \\
\text { informações encontradas }\end{array}$ & $\begin{array}{c}\mathrm{N}^{\circ} \text { de municípios } \\
\text { com informações não } \\
\text { encontradas }\end{array}$ \\
\hline Concursos & 15 & 6 \\
\hline Prestação de contas e pareceres & 10 & 12 \\
\hline RREO & 21 & - \\
\hline RGF & 21 & - \\
\hline Relação de pagamentos efetuados & 4 & 17 \\
\hline PPA & 12 & 9 \\
\hline LDO & 12 & 9 \\
\hline LOA & 12 & 9 \\
\hline
\end{tabular}

Fonte: Sites dos municípios consultados. 
A Tabela 2 apresenta resultados referentes às informações contábeis e de gestão dos recursos públicos encontrados, evidenciando que a divulgação dos relatórios impostos pela LRF, como o RREO e o RGF, está presente em todos os sites consultados. Destaca-se que, nessas seções, a linguagem apresentada é técnica, sem a descrição explicativa dos resultados dos índices, de modo que somente as pessoas com conhecimento sobre a temática terão condições de interpretá-los adequadamente.

Já no que diz respeito aos concursos públicos realizados, somente quinze locais disponibilizam as informações que envolvem o certame, o que representa, em média, $71 \%$ do total. A existência de links para prestações de contas e pareceres constam em dez municípios, e a relação de pagamentos efetuados é encontrada em apenas quatro sites consultados, índice considerado baixo para refletir uma transparência adequada sobre a movimentação financeira dos recursos nos municípios estudados.

Interessante observar que a disponibilização do Plano Plurianual, da Lei de Diretrizes Orçamentárias e do Orçamento Anual é visualizada em doze homepages consultadas, como modo de evidenciar informações complementares ao bom entendimento das políticas públicas desenvolvidas pelos gestores. Esses dados demonstram que a divulgação das informações contábeis e de gestão dos recursos públicos é praticada pela maioria dos locais estudados, colaborando para a transparência dos mecanismos formais de movimentação das contas públicas municipais. A exceção preocupante é o fato de não ser apresentada a relação dos pagamentos aos fornecedores, elemento-chave quando se considera a forma de administrar financeiramente os recursos públicos.

Por fim, na Tabela 3, buscou-se sistematizar, da seguinte forma, o levantamento de informações relativas aos aspectos legais na composição dos atos públicos ilustrados nas homepages dos locais estudados:

- licitações: editais, extratos de vencedores e demais informações;

- leis municipais: links para acesso à Lei Orgânica, leis ordinárias, decretos e outros instrumentos legais do município;

- portarias: portarias relativas a concessões funcionais aos servidores;

- cargos e salários: listagem dos cargos e salários dos servidores em geral;

- estatutos: estatuto dos servidores, na íntegra. 
Tabela 3: Informações relativas aos aspectos legais na composição dos atos públicos disponíveis nas homepages dos municípios estudados

\begin{tabular}{l|c|c}
\hline \multicolumn{1}{|c|}{ Etapa 3 } & $\begin{array}{c}\mathrm{N}^{\circ} \text { de municípios com } \\
\text { informações encontradas }\end{array}$ & $\begin{array}{c}\mathrm{N}^{\circ} \text { de municípios com } \\
\text { informações não encontradas }\end{array}$ \\
\hline Licitações & 18 & 3 \\
Leis municipais & 17 & 4 \\
Portarias & 10 & 11 \\
Estatutos & 9 & 12 \\
Cargos e salários & 6 & 15 \\
\hline
\end{tabular}

Fonte: Sites dos municípios consultados.

A Tabela 3 apresenta os resultados sobre a divulgação dos aspectos legais na composição dos atos públicos. Dados relacionados aos processos licitatórios são disponibilizados em dezoito municípios, para acesso tanto dos interessados em participar do certame quanto da população em geral, correspondendo, em média, a $85 \%$ do total de sites acessados.

Já a legislação municipal está disponível para acesso em aproximadamente 80\% dos municípios do Corede Produção, facilitando, assim, a pesquisa e a tomada de conhecimento da legislação na íntegra pela população, conforme especificidades pertencentes a cada local. No entanto, os atos referentes à situação funcional dos servidores estão acessíveis em somente dez sites consultados, o que equivale a $47,6 \%$ do total. Esse índice é considerado baixo, pois representa a transparência no que tange às sanções, às concessões de direitos e benefícios aos servidores, questões que, pelo princípio da publicidade, devem ser disponibilizadas para o conhecimento geral. Já os respectivos estatutos dos servidores municipais, instrumentos que regram todas as situações que os envolvem no desempenho de suas atividades, foram encontrados na homepage de nove municípios.

Os planos de cargos e salários constam no site de apenas seis locais consultados, perfazendo um índice médio de $28 \%$, de modo que nos demais não se tem acesso às informações que retratam a perspectiva salarial e de ascensão na carreira dos servidores.

A Tabela 4 apresenta a frequência média encontrada em cada uma das etapas estudadas: 
Tabela 4: Frequência média encontrada nos municípios estudados sobre as informações disponíveis nas homepages

\begin{tabular}{c|c|c}
\hline Etapas & $\begin{array}{c}\text { Municípios com informações } \\
\text { encontradas }\end{array}$ & $\begin{array}{c}\text { Municípios com informações } \\
\text { não encontradas }\end{array}$ \\
\hline Etapa 1 & $33 \%$ & $67 \%$ \\
Etapa 2 & $63 \%$ & $37 \%$ \\
Etapa 3 & $57 \%$ & $43 \%$ \\
\hline
\end{tabular}

Fonte: Dados primários.

A Tabela 4 evidencia o resultado dos municípios com maior destaque pelo cumprimento da transparência nas três etapas estudadas.

A etapa 1 apresenta um índice de 33\% dos municípios consultados com transparência sobre as informações de cunho geral. Conforme descrito na Tabela 1, essa disponibilização ainda se revela incipiente diante da natureza dos itens checados, necessitando, portanto, de maior atenção no processo informacional.

$\mathrm{Na}$ etapa 2, encontram-se as ações mais representativas, com a frequência média de $63 \%$ de unidades municipais com informações divulgadas, abordando aquelas de cunho contábil e de gestão dos recursos disponibilizadas aos públicos interno e externo.

Já na etapa 3 , consta o conjunto de municípios com informações colocadas à disposição da população sobre os aspectos legais da gestão. Nesse ponto, a transparência nos quesitos pesquisados alcançou $57 \%$ dos sites consultados, ao passo que nos demais isso ainda não se configura de modo uniforme.

\section{Conclusões}

Percebe-se, no Brasil, um aumento do interesse pelo acompanhamento dos atos da administração pública por parte da sociedade e dos órgãos de controle como forma de fiscalização, a qual é marcada por uma também nova demanda na disponibilização de dados e pelo acesso às informações sobre os atos empreendidos na gestão pública. Por sua vez, essa nova demanda exige uma nova postura administrativa na publicação dos dados e na própria execução de seus atos, na medida em que os entes públicos são sabedores de que o resultado será exposto ao conhecimento dos cidadãos. Assim, o processo de transparência nas organizações públicas é um marco importante em termos de democratização e de fiscalização social, pois tem a competência de agir na repressão aos atos maléficos à gestão e à ineficiência administrativa. 
Nesse sentido, este artigo buscou avaliar como os municípios pertencentes ao Corede Produção/RS disponibiliza nas suas homepages os atos de gestão dos seus governos. A metodologia foi definida como descritiva, quantitativa e delineada como survey, e a coleta de dados foi realizada nos 21 municípios selecionados para o estudo, em três etapas, que circundam a busca pelas informações consideradas relevantes ao acompanhamento da população.

Os resultados apontam que as páginas locais são utilizadas como instrumento de contato entre o Poder Público e os interessados, quesito imprescindível à implantação efetiva da transparência, por meio da disponibilização de informações, de serviços on-line, notícias, legislação, dados financeiros, assim como de dados pertinentes a programas sociais. Os índices efetivamente encontrados na pesquisa assinalam que a maioria dos municípios posta nos sites informações descritas na etapa 1, como de cunho geral, com evidência de pouca acessibilidade para menus com acessos básicos.

Já na etapa 2 , que trata de informações relacionadas à contabilidade e à gestão dos recursos públicos, estão os melhores resultados em termos de locais que buscam expor as movimentações e os resultados financeiros, excetuando-se o que se refere aos pagamentos a fornecedores, ainda com restrição de acesso aos usuários.

Na etapa 3, que aborda itens sobre os aspectos legais de gestão, percebe-se que a maioria dos municípios aderiu ao processo de transparência informacional. Ressalva-se, nesse contexto, que a efetivação desse processo de transparência depende, também, do interesse e do efetivo acompanhamento dessas informações pela sociedade, para que esta possa se caracterizar como agente fiscalizador na cobrança de seus diretos e na supervisão dos atos dos gestores públicos. Por isso, é importante destacar a necessidade de conscientização da sociedade para o acompanhamento dos atos dos gestores públicos.

Como proposta para novas pesquisas, indica-se a realização de estudos comparativos entre regiões ou entre os demais Coredes/RS, verificando a disponibilidade de informações nos portais e como elas estão dispostas ao cidadão, confrontando, assim, as diferentes realidades regionais. 


\title{
Transparency in the electronic publishing of municipal information available on web pages: an analysis of the municipalities belonging to Corede Produção/RS
}

\begin{abstract}
This article aims to assess how the municipalities belonging to Corede Produção/RS are providing data related to their acts of management, so that the local society can monitor the information from municipal public administration, once electronic means favour the supervision of the society over the acts undertaken by the public administration. The methodology consists on a research with a quantitative approach, of exploratory nature. The data collection was performed by accessing the contents from the web pages of the 21 studied cities and divided into three steps. In the first stage, results show that the studied cities publish general information on their homepages, though organized in a way that makes it difficult for citizens to have basic access. In the second stage, as to the items related to accounting and management of public resources, the best results found were related to the exposure of the information that demonstrates budget and financial transactions, except regarding payments to suppliers, still restricted from the population. Finally, the third step addresses the publishing of the legal aspects of management, in which the majority of the municipalities joined the process of informational transparency, contributing to the democratic practice in publishing the acts enacted in the administration, as recommended by the legislation.
\end{abstract}

Keywords: Information. Public resources. Sites. Transparency.

\section{Transparencia en la edición electrónica de la información disponible en sus páginas web locales: un análisis de los municipios pertenecientes a Corede Producción/RS}

\section{Resumen}

Este artículo está destinado a evaluar la forma en los municipios pertenecientes a Corede Producción/RS están proporcionando datos relacionados con actos de gestión, por lo que la empresa puede realizar un seguimiento de la información de localización desde el gobierno municipal medios electrónicos a favor de la supervisión de la empresa acerca de los actos realizados por el gobierno. La metodología consiste en la investigación con un enfoque cuantitativo, la recolección de datos exploratoria se realizó mediante el acceso al contenido de las páginas web de las 21 ciudades estudiadas y se divide en tres etapas. En la primera fase, los resultados muestran que los municipios estudiados publicar información general sobre sus páginas de inicio, pero organizado de una manera que hace que sea difícil para los ciudadanos obtener acceso básico. La segunda fase incluyó temas relacionados con la contabilidad y la gestión de los recursos públicos, los mejores resultados se han relacionado con la exposición de información que pueda servir para las operaciones presupuestarias y financieras, con excepción de los pagos a los proveedores, aunque la población restringida. Por último, el tercer paso trata con la publicación de los aspectos jurídicos de la gestión, en la que la mayoría de los municipios se han incorporado al proceso de transparencia de la información, contribuyendo a la gestión democrática.

Palabras clave: Información. Publicación. Sitios. Transparencia. 


\section{Referências}

ALEXANDRINI, Fábio et al. O atual estágio de desenvolvimento do governo eletrônico nos municípios do Alto Vale do Itajaí - Santa Catarina. In: FÓRUM INTEGRADO DE ENSINO, PESQUISA E EXTENSÃO ACAFE, UNIVILLE, 1, 2008. Anais... Disponível em: <http://digital. univille.br/digital/forum/anais.phtml?idForum $=1 \&$ acao $=$ resumos\&idArea $=1 \& c d=\# 214>$. Acesso em: 15 jan. 2012.

ARAÚJO, Inaldo da Paixão Santos; ARRUDA, Daniel Gomes. Contabilidade Pública: da teoria à prática. 2. ed. São Paulo: Saraiva, 2009.

BANDEIRA, Pedro Silveira. Uma experiência de institucionalização de regiões no Brasil: os Coredes do Rio Grande do Sul. Disponível em: <http://www.cidts.ufsc.br/articles/ArtigoBandeira. pdf>. Acesso em: 25 out. 2011.

BRASIL. Constituição (1988). Constituição da República Federativa do Brasil. Brasília, DF: Senado Federal: Centro Gráfico, 1988.

Lei Complementar 101, de 04 de Maio de 2000. Publicada no Diário Oficial da União em 05 de maio de 2000.

BRESSER PEREIRA, Luiz Carlos. Da administração pública burocrática à gerencial. Revista do Serviço Público, n. 47, v. 1, jan./abr. 1996. Disponível em: <http://www.bresserpereira.org.br/ papers/1996/95.AdmPublicaBurocraticaAGerencial.pdf>. Acesso em: 20 out. 2011.

Gestão do setor público: estratégia e estrutura para um novo Estado. In: BRESSER PEREIRA, Luiz Carlos; SPINK, Peter. Reforma do Estado e administração pública gerencial. 7. ed. Rio de Janeiro: FGV, 2006. p. 21-38. Disponível em: <http://www.bresserpereira.org.br/ papers/1998/98-GestaoDoSetorPublico-Estrategia\&Estrutura.pdf $>$. Acesso em: 02 dez. 2011.

BUGARIN, Maurício Soares; VIEIRA, Laércio Mendes; GARCIA, Leice Maria. Controle dos gastos públicos no Brasil: instituições oficiais, controle social e um mecanismo para ampliar o envolvimento da sociedade. Rio de Janeiro: Konrad-Adenauer-Stiftung, 2003.

CERVO, Amado Luiz; BERVIAN, Pedro Alcino. Metodologia científica. 5. ed. São Paulo: Prentice Hall, 2002.

CULAU, Ariosto Antunes; FORTIS, Martin Francisco de Almeida. Transparência e controle social na administração pública brasileira: avaliação das principais inovações introduzidas pela Lei de Responsabilidade Fiscal. In: CONGRESSO INTERNACIONAL DEL CLAD SOBRE LA REFORMA DEL ESTADO Y DE LA ADMINISTRACIÓN PÚBLICA, 11, Guatemala, nov. 2006. Disponível em: <http://bvc.cgu.gov.br//bitstream/123456789/1904/1/0055406.pdf>. Acesso em: 14 out. 2011.

FIGUEIREDO, Carlos Maurício. Lei de Responsabilidade Fiscal: o resgate do planejamento governamental. In: ROCHA, Valdir de Oliveira. Aspectos relevantes da Lei de Responsabilidade Fiscal. São Paulo: Dialética, 2001.

FUNDAÇÃO DE ECONOMIA E ESTATÍSTICA (FEE). Disponível em $\leq$ http://www.fee.tche.br/ sitefee/pt/content/resumo/pg_coredes_detalhe.php?corede=Produ\%E7\%E3o $>$. Acesso em: 03 jan. 2012.

GASPARINI, Diógenes. Direito administrativo. 16. ed. rev. e atual. São Paulo: Saraiva, 2011. KOHAMA, Heilio. Contabilidade pública: teoria e prática. 9. ed. São Paulo: Atlas, 2003. 
LINO, Pedro. Comentários à Lei de Responsabilidade Fiscal: lei complementar n. 101/2000. São Paulo: Atlas, 2001.

LOPES, Fábio; NERI, Lucas Oliveira; ROCHA, Murilo Porto. A Lei de Responsabilidade Fiscal sob o enfoque de controle social e transparência na contabilidade pública. Disponível em: <http://www.uesb.br/eventos/seminariodecontabilidade/artigos/artigos/A\%20Lei\%20de\%20 Responsabilidade $\% 20$ Fiscal $\% 20$ Sob $\% 200 \% 20$ Enfoque $\% 20 \mathrm{de} \% 20$ Controle $\% 20$ Social $\% 20 \mathrm{e} \% 20$ Transpar\%C3\%AAncia\%20na\%20Contabilidad.pdf>. Acesso em: 22 dez. 2011.

MAGALHÃES, Elizete Aparecida de et al. A influência da Lei de Responsabilidade Fiscal (LRF) na tomada de decisão pelos gestores públicos municipais. Cont. Vista \& Rev., Belo Horizonte, v. 16, n. 3, p. 9-16, Dez. 2005. Disponível em: <http://redalyc.uaemex.mx/src/inicio/ArtPdfRed. jsp?iCve=197016196002>. Acesso em: 03 jan. 2012.

MEIRELLES, Hely Lopes et al. Direito administrativo brasileiro. 37. ed. São Paulo: Malheiros, 2011.

OLEIRO, Walter Nunes; MENDES, Roselaine da Cruz; QUINTANA, Alexandre Costa. A contribuição da contabilidade e auditoria governamental para uma melhor transparência na gestão pública em busca do combate à corrupção. In: CONGRESSO BRASILEIRO DE CONTABILIDADE, 18, 2008. Anais... Disponível em: <http://www.congressocfc.org.br/hotsite/trabalhos_1/214. pdf>. Acesso em: 04 out. 2011.

PEREIRA, José Matias. Reforma do Estado, transparência e democracia no Brasil. Revista Acadêmica de Economia, n. 26, 2004. Disponível em: <http://repositorio.bce.unb.br/bitstream/10482/1011/1/ARTIGO_ReformaEstado.pdf>. Acesso em: 04 dez. 2011.

PEREZ JUNIOR, José Hernandez. Auditoria de demonstrações contábeis: normas e procedimentos. 3. ed. São Paulo: Atlas, 2004.

PINHO, José Antonio Gomes de; SACRAMENTO, Ana Rita Silva. Transparência na administração pública: o que mudou depois da Lei de Responsabilidade Fiscal? Um estudo exploratório em seis municípios da região metropolitana de Salvador. Revista de Contabilidade da UFBA, v. 1, n. 1, 2007. Disponível em: <http://www.portalseer.ufba.br/index.php/rcontabilidade/article/ viewArticle/2579>. Acesso em: 03 dez. 2011.

RAMOS JÚNIOR, Hélio Santiago. Princípio da eficiência e governo eletrônico no Brasil: o controle da administração pública pelo cidadão brasileiro. Disponível em: <http://www.buscalegis.ufsc. br/revistas/index.php/observatoriodoegov/article/viewFile/2014/30660>. Acesso em: 18 nov. 2011.

REZENDE, Flávio da Cunha. Desafios gerenciais para a reconfiguração da administração burocrática brasileira. Rev. Sociologias - Interface, Porto Alegre, ano 11, n. 21, jan./jun. 2009. Disponível em: <http://www.scielo.br/pdf/soc/n21/14.pdf>. Acesso em: 10 jan. 2011.

SANTOS, Alba Conceição Marquez dos. A administração pública gerencial, ago. 2003. Disponível em: <http://www.scp.rs.gov.br/uploads/AdministracaoPublicaGerencial.pdf>. Acesso em: 15 set. 2011.

SILVA, Francisco Carlos da Cruz; MACEDO, Cláudio Fernando. Controle e reforma administrativa no Brasil. In: ENANPAD, 1998. Anais... Foz do Iguaçu, 1998. Disponível em: <http://www. anpad.org.br/enanpad/1998/dwn/enanpad1998-ap-33.pdf>. Acesso em: 10 dez. 2011.

SILVA, Moacir Marques da; AMORIM, Francisco Antônio de; SILVA, Valmir Leôncio da. Lei de Responsabilidade Fiscal para os municípios: uma abordagem prática. São Paulo: Atlas, 2004. 
SLOMSKI, Valmor. Manual de contabilidade pública: um enfoque na contabilidade municipal, de acordo com a Lei de Responsabilidade Fiscal. 2. ed. São Paulo: Atlas, 2003.

SOUZA, Antônio Artur de et al. Evidenciação contábil nos municípios mineiros: atendimento ao artigo 48 da Lei de Responsabilidade Fiscal. In: CONGRESSO BRASILEIRO DE CONTABILIDADE, 18, Gramado, RS, 2008. Anais dos Trabalhos Científicos. Disponível em: <http://www. ccontabeis.com.br/18cbc/486.pdf>. Acesso em: 04 out. 2011.

STRIEDER, Inácio. A transparência democrática. Filosofia Unisinos, v. 5, n. 9, p. 167-178, jul./ dez. 2004. Disponível em: <https://bvc.cgu.gov.br//bitstream/123456789/1791/1/13filosofian9v ol5_artigo08.pdf $>$. Acesso em: 03 nov. 2011.

TORMEM, Dirceu Silvio; METZNER, Cláudio Marcos; BRAUM, Loreni Maria Dos Santos. Licitações e transparência na contabilidade pública. Disponível em: <http://www.aedb.br/seget/artigos07/680_Licitacoes\%20e\%20Transparencia\%20na\%20Contabilidade\%20Publica.pdf $>$. Acesso em: 02 nov. 2011.

VERÍSSIMO, Dijonilson Paulo Amaral. A transparência como princípio da Lei de Responsabilidade Fiscal (LRF). Disponível em: <http://www.mp.rn.gov.br/bibliotecapgj/artigos/artigo15.pdf>. Acesso em: 03 dez. 2011. 